\title{
Calibration of a Numerical Model for Heat Transfer and Fluid Flow in an Extruder
}

Hofstätter, Thomas; Pedersen, David Bue; Nielsen, Jakob Skov; Pimentel, Rodrigo; Mischkot, Michael; Hansen, Hans Nørgaard

Published in:

International Journal of Rapid Manufacturing

Link to article, DOI:

10.1504/IJRAPIDM.2016.078709

Publication date:

2016

Document Version

Peer reviewed version

Link back to DTU Orbit

Citation $(A P A)$ :

Hofstätter, T., Pedersen, D. B., Nielsen, J. S., Pimentel, R., Mischkot, M., \& Hansen, H. N. (2016). Calibration of a Numerical Model for Heat Transfer and Fluid Flow in an Extruder. International Journal of Rapid

Manufacturing, 6(1), 1-16. https://doi.org/10.1504/IJRAPIDM.2016.078709

\section{General rights}

Copyright and moral rights for the publications made accessible in the public portal are retained by the authors and/or other copyright owners and it is a condition of accessing publications that users recognise and abide by the legal requirements associated with these rights.

- Users may download and print one copy of any publication from the public portal for the purpose of private study or research.

- You may not further distribute the material or use it for any profit-making activity or commercial gain

- You may freely distribute the URL identifying the publication in the public portal 


\title{
Calibration of a Numerical Model for Heat Transfer and Fluid Flow in an Extruder
}

\begin{abstract}
This paper discusses experiments performed in order to validate simulations on a fused deposition modelling (FDM) extruder. The nozzle has been simulated in terms of heat transfer and fluid flow. In ord er to calibrate and validate these simulations, experiments were performed giving a significant look into the physical behaviour of the nozzle, heating and cooling systems. Experiments on the model were performed at different sub-mm diameters of the extruder. Physical parameters of the model - especially temperature dependent parameters - were set into analytical relationships in order to receive dynamical parameters.

This research sets the foundation for further research within melted extrusion based additive manufacturing. The heating process of the extruder will be described and a note on the material feeding will be given.
\end{abstract}

Keywords: Additive Manufacturing Technology; Fused Deposition Modelling; ABS; viscosity; simulations.

Thomas Hofstätter ${ }^{1 *}$, David B. Pedersen ${ }^{1}$, Jakob S. Nielsen ${ }^{1}$, Rodrigo Pimentel ${ }^{2}$, Michael Mischkot ${ }^{1}$, Hans N. Hansen ${ }^{1}$

1 Department of Mechanical Engineering, Technical University of Denmark, Produktionstorvet, Building 427A, DK-2800 Kgs. Lyngby, Denmark

2 Department of Micro- and Nanotechnologie, Technical University of Denmark, Ørsteds Pl., Building 345E, DK-2800 Kgs. Lyngby, Denmark

* Corresponding author: thohofs@mek.dtu.dk 


\section{Introduction}

Fused Deposition Modelling (FDM) is based on the deposition of a melted filament strand onto a surface. The melted filament is deposited to form layers in order to build a three dimensional object. A throwback of this technology is the poor surface quality and high surface roughness of the final product.

Precision Tooling for Extrusion Based Additive Manufacturing is largely absent within the industrial scene and few attempts have been herein due to FDM limitations in terms of feedstock shape and resolution through standard tooling. Vaezi et al. [27] There is, though with respect to thermopolymer rheology no distinct cause for, why extrusion based tooling systems for this AM process technology cannot be miniaturized to allow for $\mu$ FDM deposition. The polymer rheology scales linearly well below the $0.4 \mathrm{~mm}$ extruder diameter that has become the de-facto standard within FDM Chena et al. [28]. This paper aims to provide a Numerical Model for Heat Transfer and Fluid Flow in an Extruder, to form the base for further advances in tooling system for Extrusion based AM.

Earlier research has, concluded the following parameter s to be the most influencing for the surface quality of the manufactured product Anitha et al. [3]:

layer thickness,

width of the melted filament path and

printing speed.

All of the parameters are directly correlated to the diameter of the nozzle. In order to increase surface quality, a scaling of the nozzle orifice and possibly of the entire extruder can be considered. Lee et al. [23] performed a similar analysis for acrylonitrile butadiene styrene (ABS).

Whereas Anitha et al [3] were using the surface roughness parameter Lee et al. [23] were using an even more complex experiment, Sood et al. [24] focused on the dimension accuracy.

It can be stated that there exist multiple papers discussing the surface quality of FDM printed objects using Taguchi methods, which will not be discussed here any further. Masood et al. [25] mostly aimed to increase the entire system of FDM printing by a software approach for distributing the material and came to the conclusion that surface quality is directly affected by production speed. Similar to the publications presented above, they also concluded that the layer thickness plays an important role.
Literature research showed a lack of simulations of extruders for AM. Simulations concerning the heat transfer within an extruder Hofstaetter et al. b [2] as well as fluid flow within the nozzle were described in Hofstaetter et al.[1, 2]. The aim of this paper is therefor also the validation of the simulation results by Hofstaetter et al. [1, 2]. For this aim, experiments were performed on an extruder for heat transfer and heat distribution as well as fluid flow, filament feed and viscosity.

Simulations throughout this paper has been performed using Comsol Multiphysics ${ }^{\circledR} 5.0$ [11] with the modules "heat transfer in solids/fluids" and "laminar flow". The configuration is described in detail in Hofstaetter et al. [1, 2].

\section{Method}

For the validation of simulations, an Open-Hardware Extrusion system known as the "E3D HotEnd v6" extruder was simulated in terms of heat transfer and fluid flow. The primary dependencies of the simulations were the total heat transfer coefficient and pressure difference. In order to validate these parameters, experiments were carried out by heating the extruder electrically from room temperature to operating temperature monitoring the temperature of the extruder as a function of time. The extruder was operated in an environment with controlled temperature, close-loop controlled by a PID controller to target temperature while material feed was controlled through micro-stepping by an open-loop controlled stepper motor.

The viscosity model used in the simulations was validated by performing rheometer experiments in a rotational rheometer. Viscosity was measured and compared to calculated values defined by the Cross-WLF model of Shin et al. [14].

\section{Experimental setup}

The experimental validation took place on an extruder test bench developed at the Technical University of Denmark (DTU). It consists of a load cell (see Figure 1), a stepper motor (see Figure 2) and the extruder barrel including a rolling road to pose for a substrate (see Figure 3). The single components are described below.

The commonly used E3D HotEnd extruder graphically represented in Figure 4 - consists of the following components (Genuine E3D-Online reseller [5]):

- aluminium heater block heated by a cartridge with up to $25 \mathrm{~W}$,

- stainless steel heatbreak,

- aluminium heatsink and 
- brass nozzle (diameter 0.2 to $0.8 \mathrm{~mm}$ ).

Moreover, a fan can additionally be mounted. For the experiments, a DC cooling fan has been used with dimensions $30 \mathrm{~mm} \times 30 \mathrm{~mm} \times 10 \mathrm{~mm}$ with the following specifications (Xinyujie Electronics Co [6]):

air flow $1.3^{*} 10^{\wedge} 6$ to $2.1^{*} 10^{\wedge} 6 \mathrm{~mm}^{\wedge} 3 / \mathrm{s}$

static pressure 423 to $1105 \mathrm{~Pa}$

The actual extrusion process takes place in the following steps:

1. The polymer material in a solid state enters the extruder as a $1.75 \mathrm{~mm}$ filament.

2. The nozzle is kept at a temperature above melting temperature of the polymer material. In the case of $\mathrm{ABS}$, the value is chosen according to the generally used temperatures of, e.g., $230^{\circ} \mathrm{C}$. It shall be noted, that both common materials - ABS and PLA - are highly viscous polymers with nonlinear viscosity. This causes the pressure to rise unless a higher temperature or higher pressure is set at the extruder. Heat is generated by a cartridge heater and temperature is conducted via solid heat transfer. The extruder barrel is cooled by a constant heat transfer into the environment as well as by a fan placed at the heat sink.

3. While being supplied with new polymer material, the polymer closer to the outlet of the nozzle melts as passing glass transition, then elevated over the melting temperature. During this process, the dynamic viscosity changes non-linearly for nonNewtonian polymers (e.g., viscoelastic polymers). This has a major influence on the pressure within the nozzle as can be seen in the Navier-Stokes equation (3) showing the influence of the dynamic viscosity. For the reason that the viscosity is exponentially depending on the temperature as shown later in in equation (5).

4. The polymer exits the nozzle in a liquid state and is cooled by the ambient air temperature.

\section{Simulation Implementation}

The experimental validation took place to support the numerical model presented by Hofstaetter et al. a, b $[1,2]$. The most important modules used were
- heat transfer and

- laminar flow.

The calculation description is based on the processes performed during the study. Respectively, the following sections are based on the information provided by [10] concerning the calculations.

\subsection{Heat transfer (in solids/fluids)}

Heat transfer is based on the first fundamental law of thermodynamics rewritten with respect to $T$ to

$$
\rho C_{p} \mathbf{u} \cdot \nabla T=\nabla \cdot(k \nabla T)+Q
$$

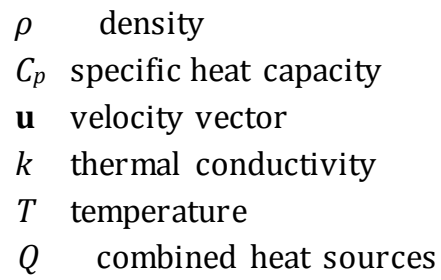

The overall heat transfer coefficient $h$ for the heat flux from the model consisting of metals in an air environment is stated by The Engineering Toolbox [11] as 5 to 37 $\mathrm{W} / \mathrm{m}^{2} \mathrm{~K}$. The value of $h=15 \mathrm{~W} / \mathrm{m}^{2} \mathrm{~K}$ has been chosen for reasons described in section 6.1 .

\subsection{Laminarflow}

The laminar flow of the polymer within the nozzle is simulated using the Navier- Stokes equation

$$
\begin{aligned}
& \rho \frac{\partial \mathbf{u}}{\partial t}+\rho(\mathbf{u} \cdot \nabla) \mathbf{u}=\nabla \cdot\left[-p \mathbf{I}+\mu\left(\nabla \mathbf{u}+(\nabla \mathbf{u})^{T}\right)\right]+\mathbf{F} \\
& \nabla \cdot(\rho \mathbf{u})=0
\end{aligned}
$$

for a stationary process.

$\begin{array}{ll}\rho & \text { density } \\ p & \text { pressure } \\ \mathbf{u} & \text { velocity vector } \\ \mathbf{F} & \text { volume force vector } \\ \eta & \text { dynamic viscosity } \\ T & \text { Temperature } \\ \mathbf{I} & \text { eye tensor }\end{array}$

As a first approach, the flow is simulated as a singlephase flow, meaning, that it only consists of the polymer The interface is used to compute the velocity and pressure fields. 


\section{Experimental Implementation}

\subsection{Heating and cooling}

An 8-bit ARM MCU based controller board with an RS-232 interface is used for the process control. The temperature of the cartridge heater is maintained by a PID loop. The temperature is set to $300^{\circ} \mathrm{C}$, to prevent that the PID loop modulate the current flow to the cartridge heater, with a $16 \mathrm{~W}$ of the maximum allowable power draw. After $140 \mathrm{~s}$ measurement time, the temperature reached 264.9 to $265.3{ }^{\circ} \mathrm{C}$, meaning, while maintaining a $100 \%$ duty cycle within the PID control loop.

Measurements were performed in intervals of $10 \mathrm{~s}$ starting from 0s and going to 140s. Experiments and simulations have been carried out without fluid flow and with the cooling fan operating. Room temperature was maintained at $20.5^{\circ} \mathrm{C}$.

According to design specifications of the extruder [12] it is possible to achieve a temperature increase from 20 to $200{ }^{\circ} \mathrm{C}$ within $65 \mathrm{~s}$ when $25 \mathrm{~W}$ is allowed to be dissipated in the cartridge heater. Measurements were performed in two different configurations:

1. Configuration with the fan turned off.

2. Configuration with the fan turned on.

\subsection{Fluid flow}

As described above, the experimental setup of Andersen et al. [4] was used for measurements. Andersen et al. identified the maximum force that the drive can exert on the filament to be $19 \mathrm{~N}$. With a filament diameter of $1.75 \mathrm{~mm}$, this correlates to a pressure of $7.9 \mathrm{MPa}$ at the extruder inlet, and with an expected pressure drop at the outlet.

If the rate of extrusion is exceeding the capabilities of the drive mechanism, slippage will occur. This is a function of the pressure required to expel material with respect to the permissible pressure that can be delivered by the system. Experiments were performed by setting a feed of $15 \mathrm{~mm}$ controlled by the diameter of the stepper motor and measuring the actual feed, meaning the actual transportation length of the filament, after the extrusion took place. If a difference of lengths are observed, the required pressure is above the $7.9 \mathrm{MPa}$. Andersen et al. [4] measured the load force directly on the filament.

\subsection{Material viscosity}

A widely used model for polymer viscosity is described in Koszkul et al, Shin et al., Jena et al. [13, 14, 15]. The socalled Cross-WLF model is based on the relation for the zero-shear viscosity:

$$
\begin{aligned}
\eta(T, \dot{\gamma}) & =\frac{\eta_{0}(T)}{1+\left(\eta_{0}(T) \dot{\gamma} / \tau\right)^{1-n}} \\
\eta_{0}(T) & =D_{1} \exp \left[\frac{-A_{1}\left(T-T_{r}\right)}{A_{2}+\left(T-T_{r}\right)}\right]
\end{aligned}
$$

$n, A_{1}, A 2, D_{1}, D_{2}, D_{3} \quad$ material model constants

$\gamma$ shear rate

$\tau$ relaxation time

$T_{r}$ arbitrary reference temperature

According to experiments by [14], the material model constants for ABS can be defined as

$$
\begin{aligned}
& \tau=3.48 \times 10^{4} \text { Pa } n=0.289 \\
& D_{1}=8.62 \times 10^{11} \mathrm{Pas} \\
& T_{r}=373.15 \mathrm{~K} \\
& A_{1}=24.96 \\
& A_{2}=51.6 \mathrm{~K}
\end{aligned}
$$

$T_{r}$ is a chosen reference temperature. Usually, the glass transition temperature is chosen. According to Shin et al. [14], this value is $100^{\circ} \mathrm{C}$, RepRap Wiki [16] stated a similar value of $105^{\circ} \mathrm{C}$.

\section{Results}

\subsection{Heating curve}

To calibrate the heat-transfer part of the numerical model, a series of experiments were performed under the conditions as described in section 4.1. Measurements were taken three times. They were affected by an average standard deviation of $0.15^{\circ} \mathrm{C}$. A graphical representation is shown in Figure 5 showing a nearly linear increase of temperature during the early heating.

The temperature gradient is slightly but steadily decreasing until it will reach a stationary value as described above. This behaviour is connected to the temperature difference between the metal of the extruder and the room temperature, which was located at $20.5^{\circ} \mathrm{C}$. The simulation was calculated with a room temperature of $20.0^{\circ}$ C. Multiple simulations showed, that the influence of the room temperature on the nozzle temperature is minimal and thus neglectible. This conforms with the robustness of the actual working conditions of the nozzle. If the nozzle was affected dramatically, printing with continuous quality would be technically impossible.

The figure also shows the heating curve calculated at 10,15 and $20 \mathrm{~W} /\left(\mathrm{m}^{2} \mathrm{~K}\right)$ heat flux outside. Statistics showed an averaged standard deviation of $5.28^{\circ} \mathrm{C}$ for $10 \mathrm{~W} /\left(\mathrm{m}^{2} \mathrm{~K}\right), \quad 1.45^{\circ} \mathrm{C}$ for $15 \mathrm{~W} /\left(\mathrm{m}^{2} \mathrm{~K}\right), 2.19^{\circ} \mathrm{C}$ for $20 \mathrm{~W} /\left(\mathrm{m}^{2} \mathrm{~K}\right), \quad 4.98^{\circ} \mathrm{C}$ for $25 \mathrm{~W} /\left(\mathrm{m}^{2} \mathrm{~K}\right)$ and $8.02^{\circ} \mathrm{C}$ for $30 \mathrm{~W} /\left(\mathrm{m}^{2} \mathrm{~K}\right)$. This makes it reasonable to set the heat flux outwards to $15 \mathrm{~W} /\left(\mathrm{m}^{2} \mathrm{~K}\right)$ in the simulations. 
The heating time as stated from the extruder specifications [12] has been measured without fan activity three times with an average time of $86 \mathrm{~s}$ and a standard deviation of $0.6 \mathrm{~s}$, which is only slightly below the measurements with fan on described above. It was not possible to find a configuration of the extruder which could fit this constraint.

A graphical representation of the temperature rise in the heater block close to the nozzle is given in Figure 6 . The nozzle was heated with $15 \mathrm{~W}$. The figure also indicates that stationary temperature is reached before 600 s. Experiments were only performed until 140s as the nozzle then has reached values greater than printing temperature of $230^{\circ} \mathrm{C}$.

\subsection{Fluid flow}

In order to ensure that experiments conducted on the experimental setup at all times was within the pressure limits of the extruder drive mechanism, close attention was paid to this limit. Similar to work performed by Andersen et al. [4], the nozzle was heated to a stationary temperature of $230^{\circ} \mathrm{C}$. A sweep of the extrusion speed showed that the stepper motor looses torque with increasing extrusion speed. This is a well-known characteristic of stepper motors described by Athani [26]. During the experiments, the set extrusion length at the inlet was held constant at $15 \mathrm{~mm}$ at an extrusion temperature of $230^{\circ} \mathrm{C}$ similar to the temperature received in the simulations. Hereafter, the actual extrusion length was measured and is shown in Figure 7. Lack of extrusion from slippage increased significantly at $100 \mathrm{~mm} / \mathrm{min}$ under a level of half the set extrusion length, indicating that the required extrusion pressure exceeded the systems capabilities. The experiment has therefore been halted.

It seems reasonable to try a linear approximation of the measurements in the range of 10 to $100 \mathrm{~mm} / \mathrm{min}$. It has been calculated using a least-square method resulting in the form of $c 1 x+c 2$ with the parameters

$$
\begin{aligned}
& c 1=-0.0492 \pm 0.003(5.1 \%)(6) \\
& c 2=15.7382 \pm 0.172(1.1 \%)(7)
\end{aligned}
$$

The relatively small error lets assume a linear slippage of the polymer filament in the stepper motor in the range of 10 to $100 \mathrm{~mm} / \mathrm{min}$. This allows to calculate the actual length of the filament extruded at certain feed velocities.

Feed velocities over $100 \mathrm{~mm} / \mathrm{min}$, however, cannot be used. During the experiments, an unsteady feed with bulging could be spotted during irregular slippage. This result might be different with another experimental setup and different friction coefficients between the materials or harder bowden cable. The bowden cable, however is necessary to prevent bending of the filament during the feeding into the extruder as the stresses change from pull to push stress when passing the stepper motor.

Reasonably smaller velocities usually result in a higher surface quality of the product, whereas higher velocities usually result in worse surface quality. Anitha et al [3]

As could be shown by Hofstaetter et al. a [2] in simulations, pressure difference and therefore extrusion velocity have a strong influence on the velocity in other directions than the nozzle velocity. The sweep over feed velocities also indicated this by the following:

- Filament extruded at low velocities exits the nozzle in a smooth form.

- Filament extruded at higher velocities tends to curl up in a non-smooth form.

These observations also correlate with the experience described by Andersen et al. [4]. This is another argument for smaller printing velocities in order to increase surface quality.

Other observations during the experiments showed, that the consistence and geometry of the filament can be changed by supporting the filament after the extruder. Pulling the filament also results in smaller filament diameters. Measurements of the filament thickness after the extrusion without an external pulling force on 15 different positions using a vernier caliper resulted in an average filament thickness of $0.37 \mathrm{~mm}$. The extrusion was performed using a $350 \mu \mathrm{m}$ nozzle diameter. This information concludes a widening of the filament after exiting the nozzle during the solidification.

\subsection{Viscosity measurements}

Calibration of the fluid flow part of the numerical model was carried out through rheometer measurements. Literature research brought only a few measurements on temperature dependence of ABS viscosity. In order to validate the measurements of Shin et al. [14], it has been decided to individually perform experiments at Vienna University of Technology. The analysis took place using Rheometer 301 by the company Anton Paar [22] (plateplate configuration) at values 160,180 and $230{ }^{\circ} \mathrm{C}$ with a slid diameter of $2 \mathrm{~mm}$. The probe hereby was placed in the analysis instrument, then melted and analyzed with the amplitude sweep, frequency sweep and time sweep.

The results for the complex viscosity can be found in Figure 8. The measurement at $160^{\circ} \mathrm{C}$ did not reach the zero shear viscosity at the converging left side of the measurements and therefore has not been used for further analysis. These measurements were then 
compared to the Cross-WLF model in order to validate the law for a viscosity over temperature relation.

The zero shear viscosities $\eta 0$ at 180 and $230{ }^{\circ} \mathrm{C}$ were found as follows including the relative error $\Delta_{\text {rel }}$ to the Cross-WLF model in equation 5: (The measurement at $160^{\circ} \mathrm{C}$ did not reach the zero shear viscosity and therefore has not been used for this comparison.)

$\begin{array}{lll}T \text { in }{ }^{\circ} \mathrm{C} & \eta 0 \text { in Pas } & \Delta_{\text {rel }} \\ 180 & 7.70 \times 10^{4} & 0.653 \\ 230 & 2.77 \times 10^{3} & 0.815\end{array}$

These values are similar and comparable to the measurements of Shin et al. [14]. All measurements tend to reach higher viscosities than the model. The model could be modified here, e.g. a higher order could be introduced. This has not been performed here.

A reason could be a different composition of $A B S$ components in the model and the experiment. This could not be validated as Shin et al. [14] did not state any further details on the ABS composition. However, Andersen et al. [4] pointed out that colour pigments influence the mechanical and thermal properties of filaments.

Calculating the model gives a viscosity over temperature relation in the region of 100 to $260{ }^{\circ} \mathrm{C}$ as shown in Figure 9. The start of the range at

$100^{\circ} \mathrm{C}$ is caused by the position of the glass transition temperature of ABS.

Moreover, equation 4 gives a relation of the dynamic viscosity depending on the shear rate which is plotted in the range of 0.01 to $10001 / \mathrm{s}$ in Figure 10. The experimental data has also been plotted.

The law presented in equation 5 and Figure 9 have also been verified by values measured by Yang et al. [17]. The model is also suitable in comparison to the model calculated by Monzon et al. [18]. As a critical value in the simulation, these values have been checked although not applied in the extruder experiment.

\section{Discussion}

A model of an extruder for AM has been implemented and calibrated by experimental data showing an overall heat transfer from the metal of the extruder into the environment of $15 \mathrm{~W} /\left(\mathrm{m}^{2} \mathrm{~K}\right)$. This value is reasonably within the range available in literature.

Heating of the nozzle showed that it is only necessary to heat the extruder with $15 \mathrm{~W}$ instead of the potential $25 \mathrm{~W}$ possible. When printing ABS, it is not necessary to use the entire power of the electric heating system. This, however, might be necessary for different materials.
The maximal extrusion speed at the inlet for $A B S$ is located below $100 \mathrm{~mm} / \mathrm{min}$. Above this value, slippage of the stepper motor becomes irregular and nondeterministic. This sets a limit to printing speed.

The filament diameter after extrusion lies above the nozzle diameter and can be changed by applying an external pulling force. The filament changes its size after exiting the nozzle and during solidification.

Performing a parameter sweep with feeding velocities of 10 to $100 \mathrm{~mm} / \mathrm{min}$ showed a smooth form of the extruded filament at low extruding velocities and an uneven and curled shape at higher velocities. This behaviour results from higher velocities in other directions (see [2]) than the nozzle within the polymer at higher pressure differences between inlet and outlet. The reasonable feeding speed lies below $20 \mathrm{~mm} / \mathrm{min}$ where the slippage is located at lower values.

Viscosity measurements compared to the CrossWLF model of Shin et al. [14] brought similar results to Yang et al., Monzon et al. $[17,18]$. The Cross-WLF model has been validated with three experimental settings at three different temperatures 160,180 and $230{ }^{\circ} \mathrm{C}$ where 180 and $230{ }^{\circ} \mathrm{C}$ reached zero shear viscosity. It can be concluded that the Cross-WLF model by Shin et al. [14] delivers the values to expect from experiments.

\section{Conclusion}

A numerical model for heat transfer and fluid flow within extruders for AM has been developed. Calibration of this model has been described throughout this paper from values for which literature states multiple options or data ranges. In order for the model to produce valid results, these values were successfully experimentally identified. The results were presented in section 7 . From this, it can finally be concluded that:

Viscosity needs to be considered carefully when defining a model as viscosity exponentially depending on the polymer temperature. Temperature also has a great influence on the viscosity of the polymer and as a consequence also on the surface quality of the printed object. The overall heat transfer coefficient plays an important role in the height of the temperature within the extruder, and could likewise be identified through experimental results. Throughout experimental work, concerns were that filament slippage could lead to false results due to the connected pressure drop inside the extruder system. This exact mechanism also defines the maximal printing speed of an extrusion based 3D printer. Finally, throughout the experimental studies, it was noticed that the polymer widens after the extrusion 
during solidification. This fact needs to be considered when creating the printing geometry and motion control of the printer.

\section{References}

1. Thomas Hofstaetter, Rodrigo Pimentel, David B. Pedersen, Michael Mischkot, and Hans N. Hansen. Simulation of a downsized fdm nozzle. In Comsol Conference, 2015.

2. Thomas Hofstaetter. Diploma Thesis: Analysis and Discussion on the Effciency and Feasibility of Downsizing an FDM Printer. Vienna University of Technology, to appear 2015.

3. R Anitha, S Arunachalam, and P Radhakrishnan. Critical parameters influencing the quality of prototypes in fused deposition modelling. Journal of Materials Processing Technology, 118(1):385-388, 2001.

4. Sebastian Aagaard Andersen and Lisa Rabenow. Project report: Fdm test bench. DTU Mechanical Engineering, 2015.

5. Genuine E3D-Online reseller. E3Dv6 Documentation (http://wiki.e3donline.com/wiki/E3D-v6 Documentation). visited 2015-08-12.

6. Xinyujie Electronics Co. Product site DC cooling fan (http://xinyujie.applianceschina.com/Product Look.php ProID=207890). visited 2015-08-17.

7. Pololu. Product data sheet for stepper motor (https://www.pololu.com/file/0J715/SY42STH3816 84A.pdf). visited 2015-08-24.

8. RepRap.me. Product site ABS 1.7mm Natural (http://reprap.me/abs-1-7mm-natural.html). visited 2015-08-24.

9. Olagoke Olabisi and Kolapo Adewale. Handbook of thermoplastics, volume 41. CRC press, 1997.

10. Comsol Multiphysics Inc. Comsol Multiphysics Help. Comsol Multiphysics Inc., 2015.

11. The Engineering ToolBox. The Engineering ToolBox (http://www.engineeringtoolbox.com/). visited 2015-07-07.

12. Genuine E3D-Online reseller. E3D-Online (http://e3d-online.com/E3D-v6). visited 20150707.

13. J Koszkul and J Nabialek. Viscosity models in simulation of the filling stage of the injection molding process. Journal of Materials Processing Technology, 157:183-187, 2004.
14. Hyeyoung Shin and Eun-Soo Park. Analysis of incomplete filling defect for injection-molded air cleaner cover using moldflow simulation. Journal of Polymers, 2013, 2013.

15. RK Jena, X Chen, CY Yue, and YC Lam. Viscosity of coc polymer (topas) near the glass transition temperature: Experimental and modeling. Polymer Testing, 29(8):933-938, 2010.

16. RepRapWiki. ABS (http://reprap.org/wiki/ABS). visited 2015-07-16.

17. Kumin Yang, Shi-Ho Lee, and Jong-Man Oh. Effects of viscosity ratio and compatibilizers on the morphology and mechanical properties of polycarbonate/acrylonitrile-butadiene-styrene blends. Polymer Engineering \& Science, 39(9):1667-1677, 1999.

18. Mario D Monz'on, Ian Gibson, Antonio N Ben'itez, Luis Lorenzo, Pedro M Hern'andez, and Mar'ia D Marrero. Process and material behavior modeling for a new design of microadditive fused deposition. The International Journal of Advanced Manufacturing Technology, 67(9-12):2717-2 726, 2013.

19. Makerbot. Product website (http://store.makerbot.com/europe). visited 201511-01.

20. Mendel. Product website (http://reprap.org/wiki/Mendel). visited 2015-1101.

21. Rasperry Pie. Product website (https://www.raspberrypi.org/). visited 2015-1101.

22. Anton Paar. Product website (http://www.antonpaar.com/us-en/). visited 2015-11-01.

23. Lee, BH et al. (2005)._Optimization of rapid prototyping parameters for production of fexible ABS object In: Journal of Materials Processing Technology 169.1, pp. 54_61.

24. Sood, Anoop Kumar et al. (2009). _Improving dimensional accuracy of Fused Deposition Modelling processed part using grey Taguchi method_ In: Materials \& Design 30.10, pp. 4243_4252.

25. Masood, Syed H (1996). _Intelligent rapid prototyping with fused deposition modelling. In: Rapid Prototyping Journal 2.1, pp. 24_33. 
26. V. V. Athani, Stepper Motors - Fundamentals, Applications and Design, New Age International Publishers, 1997, 2005

27. Mohammad Vaezi \& Hermann Seitz \& Shoufeng Yang, A review on 3D micro-additive manufacturing technologies, Int J Adv Manuf Technol (2013) 67:1721-1754

28. S.C. Chena, R.I. Tsaia, R.D. Chienb, T.K. Lina, Preliminary study of polymer melt rheological behavior flowing through micro-channels, International Communications in Heat and Mass Transfer 32 (2005) 501-510 


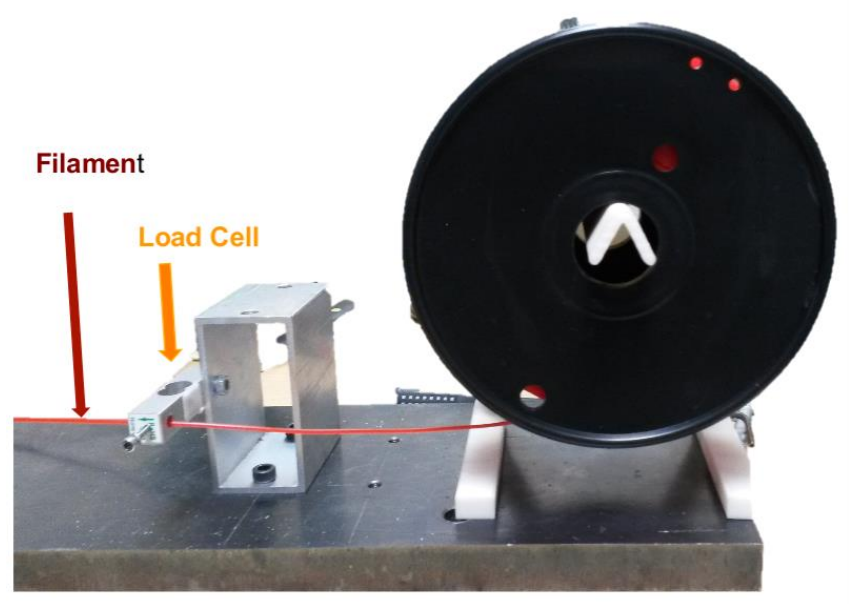

Figure 1 Start of test setup, load cell [4]

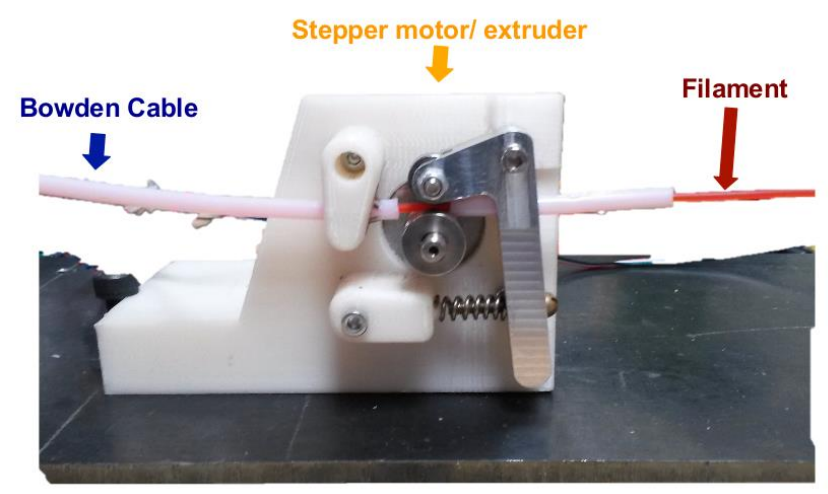

Figure 2 Step two of test setup, stepper motor [4]

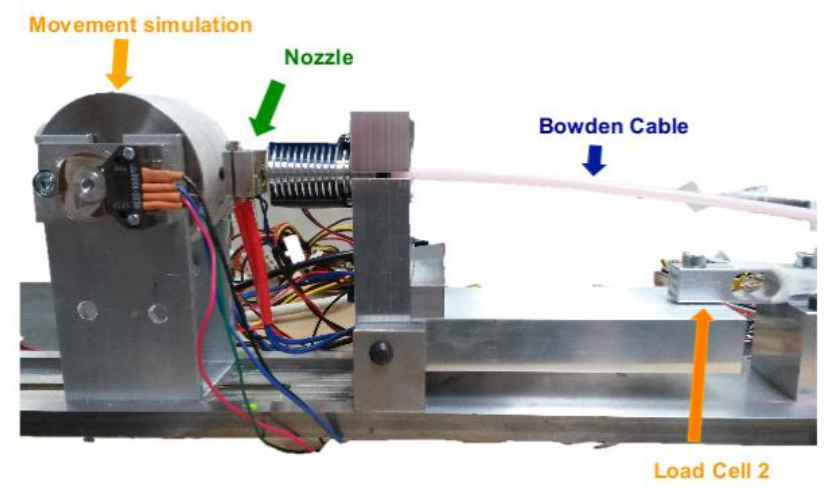

Figure 3 Step three of test setup, nozzle and movement simulation [4]

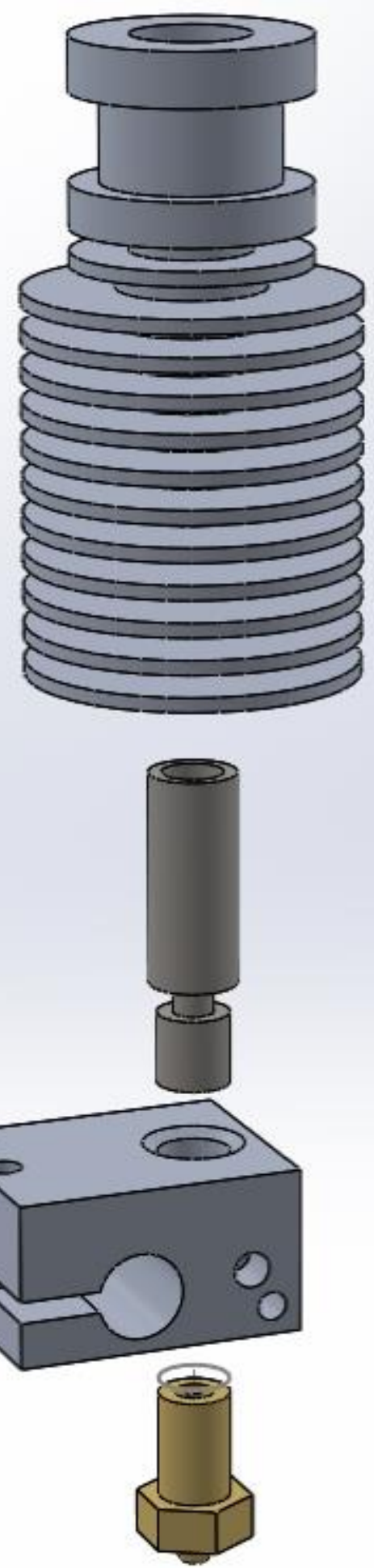

Figure 4 E3D HotEnd extruder; from top to bottom: heatsink, heatbreak, heater block, nozzle (modi_ed from a model from GrabCAD) 


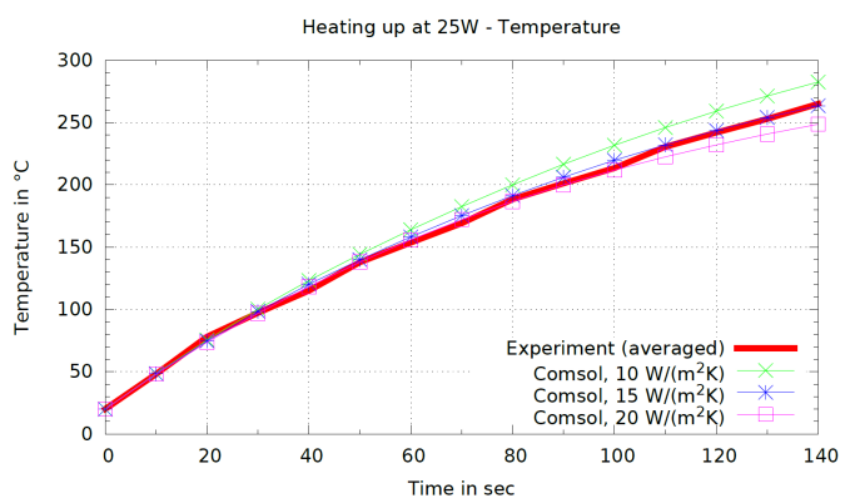

Figure 5 Temperature during heating with $25 \mathrm{~W}$ includingsimulations

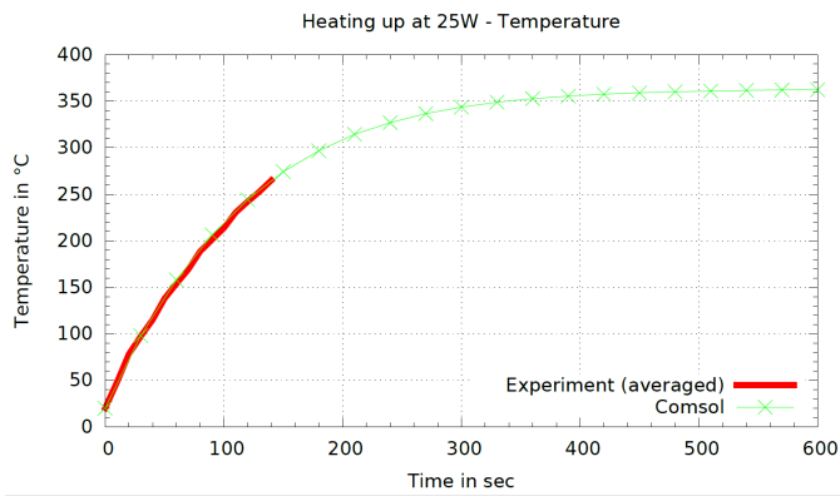

Figure 6 Temperature close to the nozzle in simulations and experiments

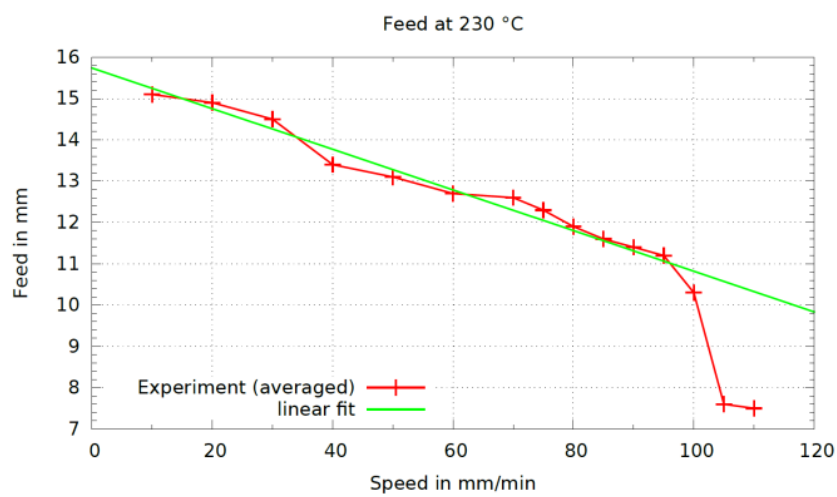

Figure 7 Slippage of filament, shown as the actual extruded length for an intended extrusion of $15 \mathrm{~mm}$

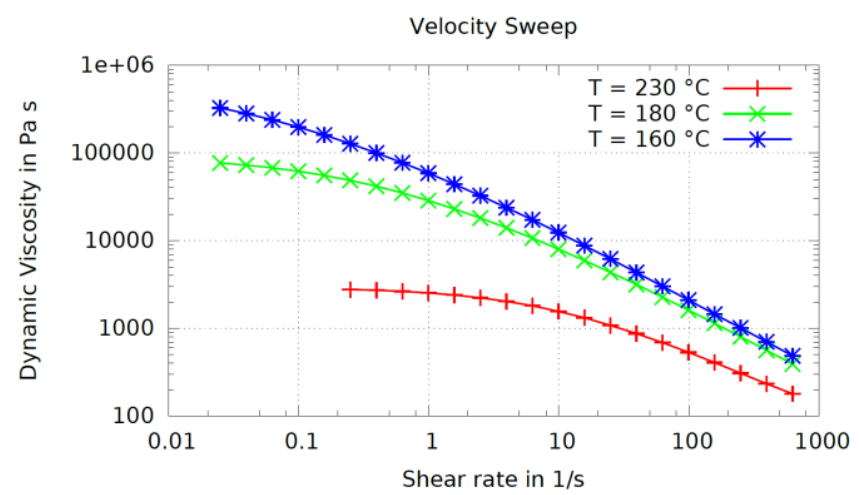

Figure 8 Experimentally gathered complex viscosity at 160,180 and $230{ }^{\circ} \mathrm{C}$

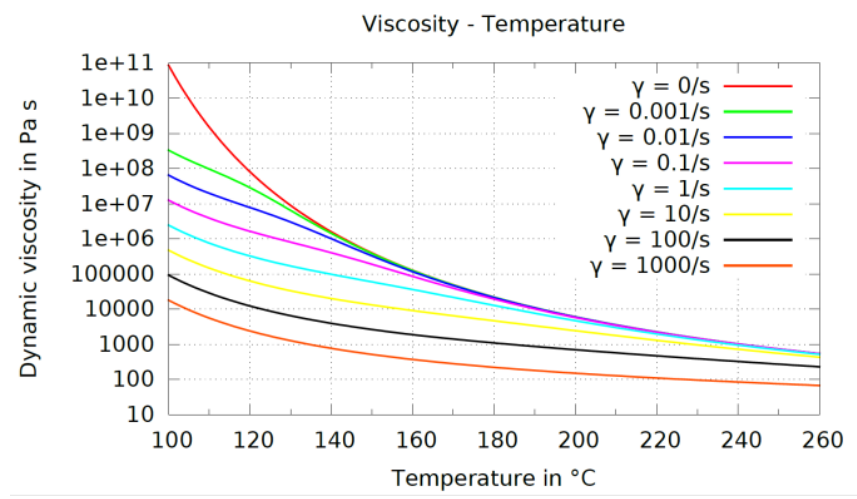

Figure 9 Viscosity over temperature in the range of 100 to $260{ }^{\circ} \mathrm{C}$

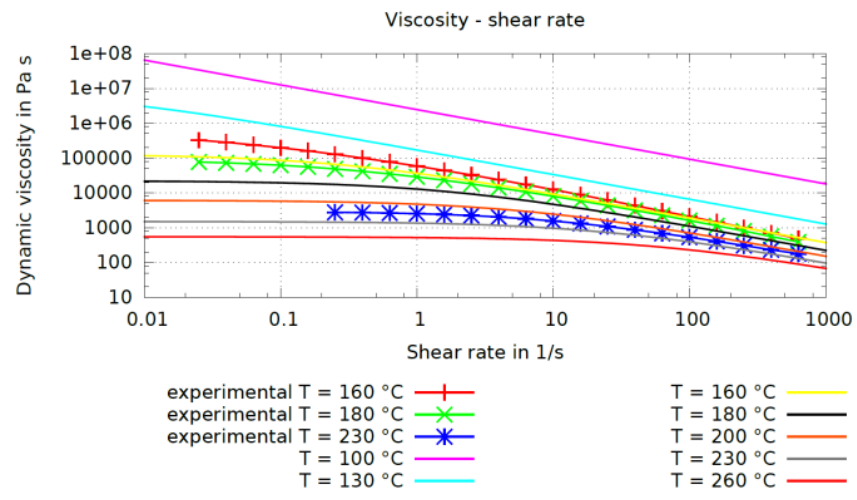

Figure 10 Viscosity over shear rate in the range of 0.01 to $10001 / \mathrm{s}$ 